\title{
Are TKIs favourable for the elderly with non-small-cell lung cancer?
}

\author{
Sabrina Rossi ${ }^{1}$, Ettore D'Argento ${ }^{1}$, Giovanni Schinzari ${ }^{1}$, Vincenzo Dadduzio ${ }^{1}$,

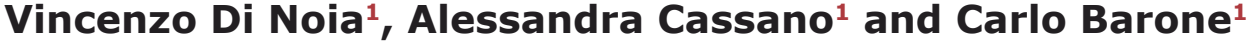 \\ ${ }^{1}$ Department of Medical Oncology, Catholic University of Sacred Heart, Largo A. Gemelli, Rome, Italy \\ Correspondence to: Ettore D'Argento, email: ettore.dargento@policlinicogemelli.it \\ Keywords: gefitinib; afatinib; elderly; concomitant medications; efficacy; Gerotarget \\ Received: March 17, $2016 \quad$ Accepted: April 22, $2016 \quad$ Published: May 17, 2016
}

ABSTRACT

Background: Epidermal Growth Factor Receptor (EGFR) tyrosine-kinase inhibitors (TKIs) have changed treatment strategies for patients with advanced non-small-cell lung cancer (NSCLC) harbouring mutations in EGFR gene. This retrospective analysis assessed efficacy and safety of TKIs in elderly compared to younger patients.

Patients and methods: 49 patients with advanced NSCLC and mutations in exon 19 or 21 receiving a first-line therapy with TKIs were included and divided into patients aged $<\mathbf{7 0}$ years and patients aged $\geq \mathbf{7 0}$ years. Primary endpoints were progression free survival (PFS), response rate (RR) and clinical benefit in terms of quality of life; secondary endpoint was overall survival (OS).

Results: Median PFS was significantly longer in elderly in comparison to younger patients (12.6 and 5.6 months, respectively; $p=.008$ ). RR was $64 \%$ in younger patients and $75 \%$ in elderly population. Eighteen out of $20(90 \%)$ elderly patients treated with gefitinib experienced symptoms relief and upgrading of performance status. No difference in terms of OS was found $(p=.34)$.

Conclusion: TKIs seem more effective in elderly than in younger patients affected by NSCLC with an EGFR gene mutation. We hypothesize that the main difference between the two populations is the number of medications related to concomitant comorbidities that cause an increased plasma level of TKIs.

\section{INTRODUCTION}

Lung cancer is the leading cause of cancerrelated death worldwide; about $75-80 \%$ of lung cancers have a non-small-cell histology (NSCLC). [1] Due to prolongation of life expectancy, most of cases are diagnosed in patients over the age of 65 and the median age at diagnosis is 70 years. [2]. In elderly patients, comorbidities, polypharmacy, impaired liver or kidney function are common and influence treatment decisions. Many studies evaluating efficacy and safety of chemotherapy in the elderly suggest that performance status and comorbidities have a greater prognostic importance than age itself. [3, 4].

In the last decade the discover of new molecular targets has deeply modified treatment strategies for patients with advanced NSCLC harboring mutations in epidermal growth factor receptor (EGFR), that predict both a better response to EGFR tyrosine-kinase inhibitors (TKIs: gefitinib, erlotinib, afatinib) and a longer progression-free survival which translates in increased overall survival. [5, 6, 7]. Nevertheless, body mass index, residual organ function and concomitant medications might affect either TKIs clearance in elderly patients or their efficacy and safety. However, clinical trials are conducted in selected patients aged 75 years or less that do not reflect people treated in clinical practice. Recently, several reports confirmed the safety and efficacy of gefitinib, a reversible EGFR tyrosine-kinase inhibitor, in mutated patients aged $>70$ years, $[8,9]$ whereas no study has specifically evaluated afatinib, a selective irreversible ErbB family blocker, in this subset of patients. 
Pharmacokinetics characteristics of gefitinib and afatinib are different both in terms of bioavailability and drug metabolism that is influenced by individual variability. Their oral absorption is slow to moderate with substantial inter-individual differences in the extent of gastrointestinal tract mucosa. Gefitinib undergoes extensive hepatic metabolism predominantly by cytochrome P450 (CYP)dependent enzymes; in contrast, afatinib undergoes minimal biotransformation and oxidative CYP-mediated metabolism is of negligible importance. Thus, gefitinib has an important potential for interaction with other agents that are metabolised by or are inhibitors/inducers of the CYP-related enzymes. Both gefitinib and afatinib undergo prevalent faecal excretion while renal elimination is responsible for $<5 \%$ of the administered dose. [10]

In the present retrospective analysis we have evaluated efficacy and safety of gefitinib and afatinib in elderly ( $\geq 70$ years) compared to younger patients.

\section{RESULTS}

\section{Patients' characteristics}

Forty-nine out of 54 patients with histologically proven diagnosis of NSCLC (adenocarcinoma or other non-small cell histology) and with an EGFR gene mutation treated in our center between June 2010 and July 2014 were considered eligible. Most patients were female (74\%) and never smokers (75\%). Median age at diagnosis was 63 years (range 44-69) and 75 years (range 72-81) in group A and $\mathrm{B}$, respectively; 8 out of 24 patients in group B (33\%) had 80 years. Most of patients had a PS (ECOG) $1(52 \%$ in group A and 54\% in group B); performance status was equal or superior to 2 in $8 \%$ of patients in group A and in $25 \%$ of elderly patients. In group A, $20 \%$ of patients had no comorbidities, $72 \%$ had one or two comorbidities, $8 \%$ more than two. On the other hand, $67 \%$ of elderly patients had one or two comorbidities, 33\% more than two comorbidities, $0 \%$ had no comorbidities. The most frequent concomitant diseases in the whole population were hypertension, diabetes and cardiac comorbidities (ischemic or arrhythmic cardiac disease); 6 patients of elderly group and 1 in the youngest group had a history of other malignancies within 5 years prior to diagnosis of NSCLC. In $90 \%$ of cases the histologic subtype of NSCLC was adenocarcinoma, in 10\% adeno-squamous carcinoma. A total of 29 patients (59\%) had a deletion in exon 19 (17 in group A and 12 in group B) and 20 (41\%) had a point mutation in exon 21 ( 8 in group $A$ and 12 in elderly group). All patients received a treatment with TKIs as first-line therapy. Out of 49 patients, 5 were treated with afatinib $40 \mathrm{mg}$ /daily (1 in group A, 4 in group B) while 44 of them received gefitinib $250 \mathrm{mg} /$ daily (24 in group A, 20 in group B). Treatment was continued until disease progression, unacceptable toxicity or patient's withdrawal. Patients' characteristics are summarized in Table 1.

\section{Response and survival}

After a median follow up of 36 months, 23 patients in group A (92\%) and 18 in group B (75\%) had experienced disease progression after first-line TKI treatment and overall 7 are still alive (3 and 4 in group A and $\mathrm{B}$, respectively). A significant difference in terms of median PFS between younger and elderly population was found: 5.6 and 12.6 months, respectively ( $p=.008$; HR 0.46 ; 95\% CI 0.24-0.87) (Figure 1). Conversely, OS was not significantly different between younger and elderly group (15.03 vs. 18.6 months; HR 0.76; 95\%CI 0.42$1.38 ; p=.34)$. $\mathrm{RR}$ in group A was $64 \%$ in group A and $75 \%$ in group $\mathrm{B}$; the difference was not significant ( $p=$ .89). No patient achieved a complete response. In group A $7 / 25$ patients $(28 \%)$ received a second-line treatment and $5 / 25(20 \%)$ a third-line therapy, while only $4 / 24(16.6 \%)$ and $2 / 24(8.3 \%)$ of elderly patients received a second and third-line treatment, respectively.

The incidence of exon 21 point mutation, which is considered a negative prognostic factor in terms of survival in comparison to exon 19 deletions $[11,12,13]$, was greater in elderly population than in group A $(50 \%$ vs $32 \%$ ). Despite this unfavourable distribution, in our analysis no difference in terms of PFS was found in elderly population carrying exon 19 and exon 21 mutations (14.3 vs 12.6 months, respectively; HR 0.82 ; 95\%CI 0.32 $2.12 ; p=.63)$. However, OS showed a trend toward an advantage in elderly patients with exon 19 deletions (22.4 months) in comparison to those carrying exon 21 point mutation (15.1 months); in spite of the apparently large difference, the result was not statistically significant (HR 0.79 ; 95\% CI 0.34-1.82; $p=.53$ ).

An interesting finding was the difference in terms of median PFS of elderly patients receiving gefitinib compared to those receiving afatinib, which resulted significantly longer in the first ones $(p<.0001)$. After a median follow up of 36 months, all patients (100\%) treated with afatinib and $14(70 \%)$ who received gefitinib experienced disease progression after first-line. Neverthess, this result is just a rough indication due to the small sample size of afatinib group.

\section{QoL and tolerability}

Most patients had an improvement of performance status after treatment with TKIs, independently on age: 13 out of 25 in group A (52\%) and 14 out of 24 elderly patients (58\%). Eighteen (90\%) out of 20 elderly patients treated with gefitinib experienced symptoms relief and upgrading of PS (ECOG) from a median of 2 to a median of 1 . 


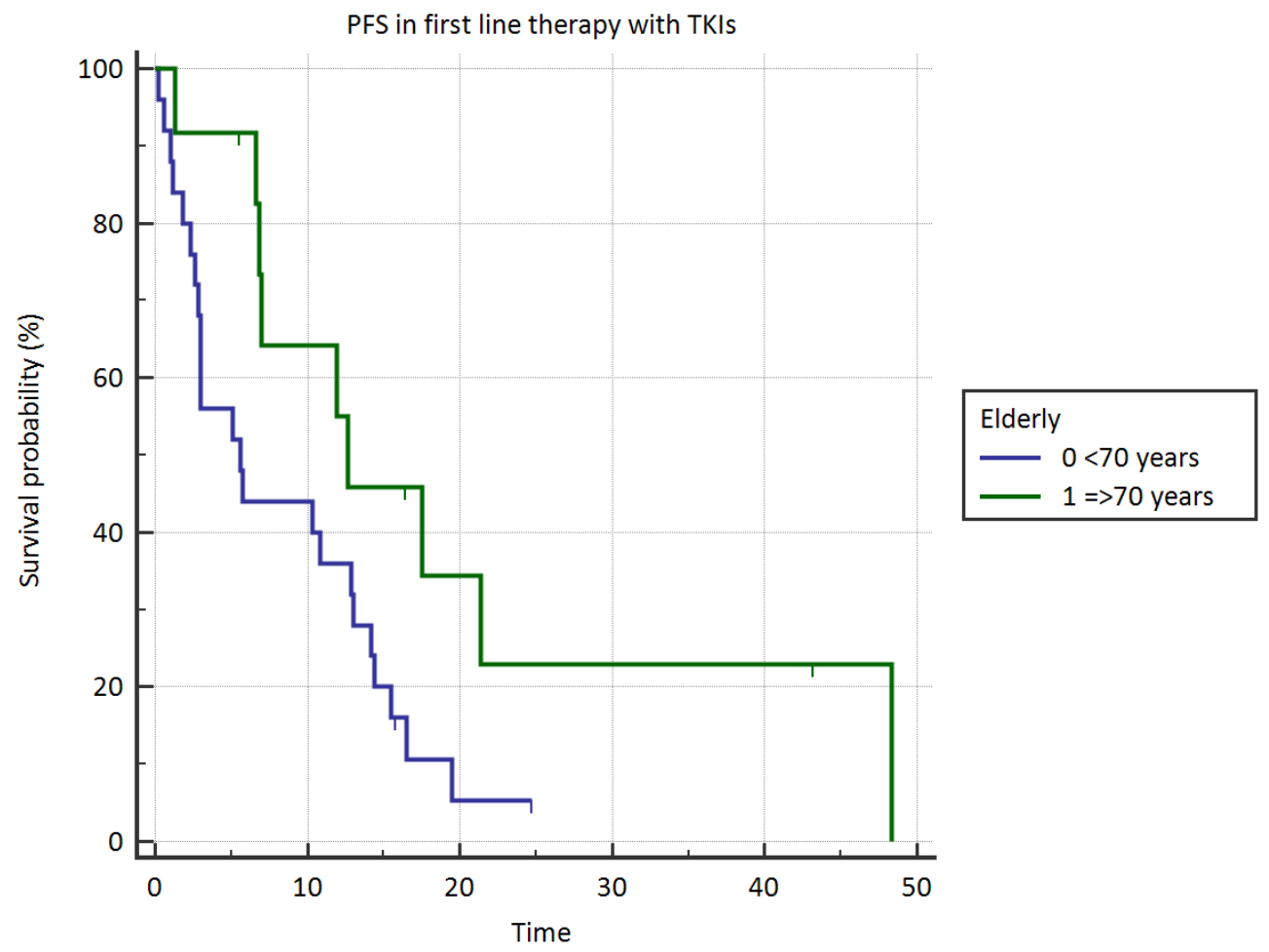

Figure 1: Progression free survival in elderly vs. younger patients.

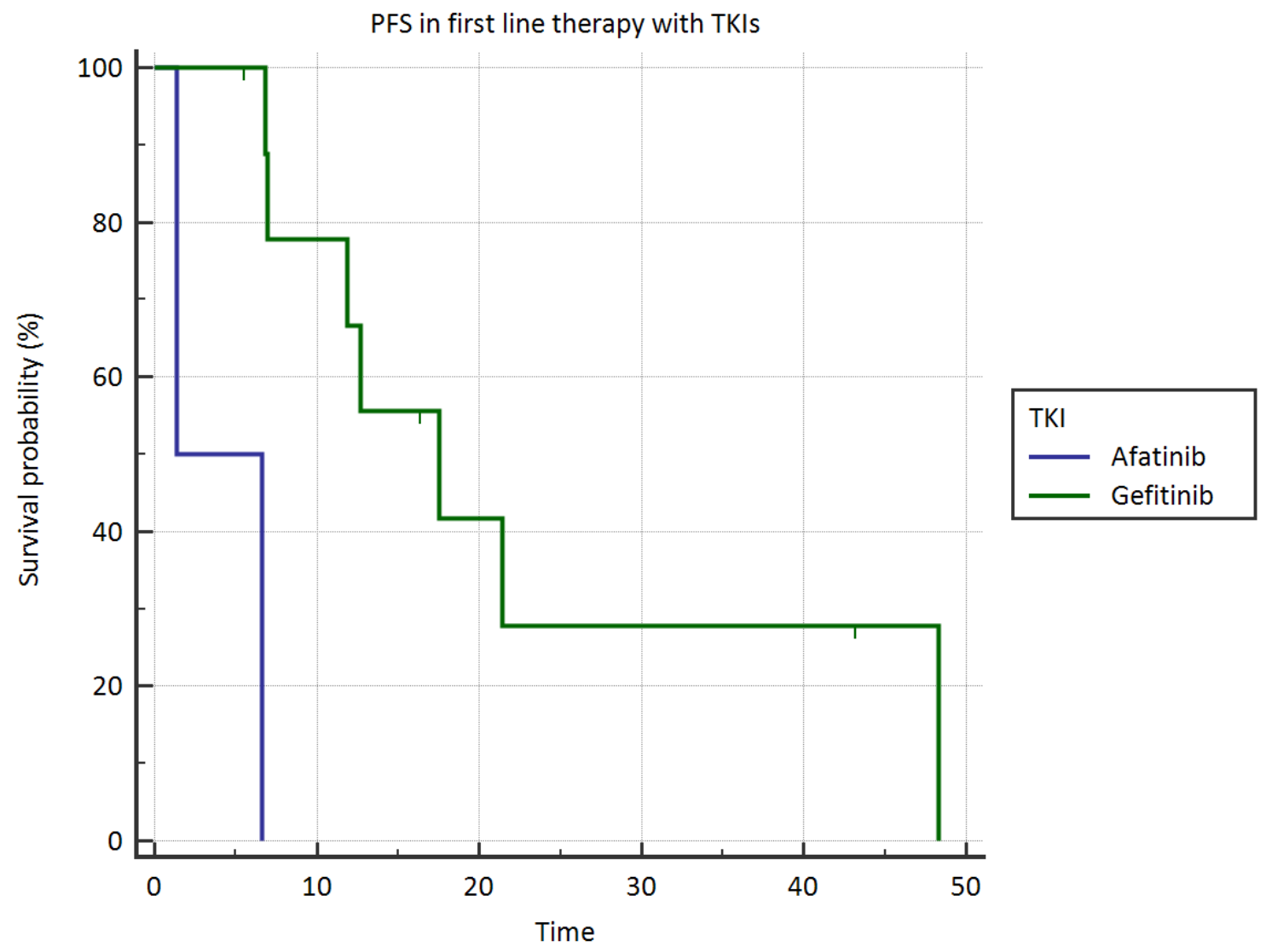

Figure 2 : Progression free survival in elderly patients treated with gefitinib vs. afatinib 
Table 1: Patients' characteristics

\begin{tabular}{|c|c|c|}
\hline & $\begin{array}{l}\text { GROUP A (<70 years) } \\
n .25\end{array}$ & $\begin{array}{l}\text { GROUP B ( } \geq 70 \text { years) } \\
n .24\end{array}$ \\
\hline Median Age & 63 ( range 44-69) & 75 (range 72-81) \\
\hline Smokers & $27 \%$ & $25 \%$ \\
\hline $\begin{array}{r}\text { Gender } \\
\quad \text { - Female }\end{array}$ & $80 \%$ & $76 \%$ \\
\hline \multicolumn{3}{|l|}{ PS (ECOG) at diagnosis } \\
\hline 0 & $10 / 25(40 \%)$ & $5 / 24(20 \%)$ \\
\hline 1 & $13 / 25(52 \%)$ & $13 / 24(54 \%)$ \\
\hline$\geq 2$ & $2 / 25(8 \%)$ & $6 / 24(25 \%)$ \\
\hline \multicolumn{3}{|l|}{ Functional Impairment } \\
\hline - no comorbidities & $5 / 25(20 \%)$ & $0 / 24(0 \%)$ \\
\hline - 1 or 2 comorbidities & $18 / 25(72 \%)$ & $16 / 24(67 \%)$ \\
\hline - $>2$ comorbidities & $2 / 25(8 \%)$ & $8 / 24(33 \%)$ \\
\hline \multicolumn{3}{|l|}{ Most frequent comorbidities } \\
\hline Hypertension & $12 / 25(48 \%)$ & $20 / 24(83 \%)$ \\
\hline Diabetes & $4 / 25(16 \%)$ & $8 / 24(33 \%)$ \\
\hline Cardiac comorbidities & $3 / 25(12 \%)$ & $4 / 24(17 \%)$ \\
\hline $\mathrm{BPH}^{*}$ & $1 / 25(4 \%)$ & $4 / 24(17 \%)$ \\
\hline History of other malignancies & $1 / 25(4 \%)$ & $6 / 24(25 \%)$ \\
\hline Other & $7 / 25(28 \%)$ & $8 / 24(33 \%)$ \\
\hline \multicolumn{3}{|l|}{ First line treatment } \\
\hline Gefitinib & $24 / 25(96 \%)$ & $20 / 24(83 \%)$ \\
\hline Afatinib & $1 / 25(4 \%)$ & $4 / 24(17 \%)$ \\
\hline \multicolumn{3}{|l|}{ EGFR mutation } \\
\hline 19 & $17 / 25(68 \%)$ & $12 / 24(50 \%)$ \\
\hline 21 & $8 / 25(32 \%)$ & $12 / 24(50 \%)$ \\
\hline
\end{tabular}

* Benign prostatic hyperplasia

The most frequent adverse events were rash, diarrhea and fatigue. There was no treatment-related death both in younger and older population and only few adverse events of grade $3 / 4$, comparable in the two groups. There was a trend toward a more frequent and severe cutaneous rash between elderly patients ( $50 \%$ of all grades) than in younger population ( $40 \%$ of all grades), but the difference is not statistically significant. However, five patients of group B required dose reduction for treatment-related rash, six patients had a dose delay for diarrhea and one patient experienced interstitial lung disease, but there was no treatment interruption due to serious adverse event.

\section{DISCUSSION}

In the present study, treatment with TKIs seems more effective in elderly than in young patients affected by advanced NSCLC with an EGFR gene mutation; PFS was significantly longer in elderly, but OS was comparable in the two groups, suggesting that treatment with TKIs influences tumor response and prolongs the duration of first-line therapy but does not affect long-term survival, probably as a consequence of second and third line treatment, that were more common in the youngest population. No differences in terms of PFS were found in exon 21 versus exon 19 mutated elderly patients, but those carrying exon 19 deletions had an advantage in terms of OS (+7.3 months). Therefore, the known negative prognostic impact of exon 21 point mutations, [12, 13, 14] that were more frequent in elderly group, might have contributed to nullify the advantage in PFS. In a previous retrospective analysis, Wheatley-Price et al. demonstrated the efficacy of erlotinib in second or third-line comparing elderly and younger patients enrolled in BR.21 study; also in this case, it was found a better response rate $(70 \%$ vs 59\%) and a longer PFS (39 vs 34 weeks) in elderly group, but the difference was not statistically significant. [14]. Similarly, in POLARSTAR study elderly Japanese patients with previously treated NSCLC, not selected for EGFR mutations, showed a trend toward a longer PFS in comparison to younger group, even if not statistically significant.[15]. 
The reason for longer PFS in elderly patients is matter of discussion. Response to TKIs is correlated with EGFR mutations and EGFR gene copy number; there is no clear evidence of different EGFR expression in elderly even if in the analysis from Wheatly-Price a higher number of EGFR copies was found in elderly patients. However, this finding does not explain the longer PFS in elderly patients not selected for EGFR mutations and treated with TKIs in the POLARSTAR study.[15] Alternatively, body mass index, residual organ functions and metabolic effects of concomitant medications might affect TKIs clearance as well their efficacy and safety. No age-dependent effect has been reported on pharmacokinetic either of gefitinib or afatinib, [10] but it has been demonstrated that, in contrast to afatinib, gefitinib undergoes extensive hepatic metabolism by cytochrome P450 (CYP)-dependent enzymes suggesting the possibility of significant interactions with other agents metabolised by CYP-related enzymes. By the contrary, mild and moderate hepatic impairment, as it might be observed in patients with liver metastases, does not seem to have a major impact on exposure of TKIs. Moreover, both gefitinib and afatinib have a prevalent faecal excretion with $<5 \%$ of drug excreted in the urine, so excluding that a mild or moderate renal impairment might influence the exposure to TKIs. Therefore, excluding effects of age- or cancer-related impairment of renal and hepatic function on a greater exposure to afatinib and gefitinib in elderly patients, we hypothesize that polypharmacy might be responsible of an altered clearance of TKIs. Drugs interacting both with transporter molecules at enterocyte level as P-gp (ATP-binding cassette drug transporter P-glycoprotein 1) and liver metabolizing CYP-dependent enzymes affects bioavailability of TKIs. Gefitinib and afatinib are a substrate and afatinib is also an inhibitor of P-gp; strong P-gp inhibitors (ketoconazole, itraconazole, amiodarone, verapamil etc) can increase exposure to afatinib, especially if administered nearby the TKIs. However, most interactions involve drugmetabolizing CYP-related enzymes and gefitinib; CYPinhibitors (ciprofloxacin, clarithromycin, dexamethasone, fluconazole, metronidazole, ketoconazole, omeprazole, ranitidine, valproic acid etc) could increase plasma levels of gefitinib, thus inducting both a better therapeutic activity and a greater percentage of adverse reactions. Moreover the activity of these enzymes could be constitutively reduced in elderly by age. $[16,17]$. Retrospective studies suggest that the severity of rash or diarrhea correlates with exposure to TKIs. $[18,19]$. Actually, in our study elderly patients experienced more toxicities and were more likely to have grade $\geq 3$ rash, fatigue and diarrhea, suggesting a higher plasma concentration of TKIs in this group. Moreover, our data suggest a trend toward a longer PFS in elderly patients who underwent gefitinib rather than afatinib - which is not an inhibitor or inducer of CYP- related enzymes - probably due to the different metabolism and drug interactions, although these results are biased by the small sample size of the afatinib subgroup. Since it was demonstrated in phase I studies that gefitinib $250 \mathrm{mg} /$ die is about one-third of the maximum tolerated dose, [20]. we can assume that gefitinib might be more effective than afatinib in elderly because concomitant medications cause a higher but tolerable plasma concentration of this TKI.

In conclusion the present study shows that firstline therapy with TKIs is feasible in elderly population and is more effective in terms of response rate and PFS in comparison to the younger subgroup. The combined effect of concomitant medications on transport and metabolism of gefitinib and afatinib may induce increased plasma levels of TKIs, that translate in greater efficacy and toxicity.

\section{PATIENTS AND METHODS}

\section{Patients' selection}

This retrospective analysis includes 49 patients (aged $\geq 18$ years) with histologically proven metastatic NSCLC and mutations in exon 19 or 21 treated in our center between 2010 and 2014. All mutational analyses were conducted in the laboratory of Diagnostic Molecular Pathology at the Catholic University of Sacred Heart (Rome, Italy). Taking into account the age at the beginning of therapy, patients were divided into two groups: group A (patients aged $<70$ years) and group B (patients aged $\geq 70$ years). Inclusion criteria for selection were: a) first-line therapy with TKIs (gefitinib or afatinib); b) imaging assessment (Computed Tomography or Positron Emission Tomography-Computed Tomography) performed at regular intervals (no longer than 3 months); c) complete informations regarding comorbidities and concomitant medications. Data on patients' functional status (performance status - PS ECOG), comorbidities and concomitant medications have to be available at the time of analysis. Patients were excluded if harboring more than one mutation in two or more exons or in case of resistance mutations (p.T790M, exon 20 insertion). Patients whose diagnosis was performed after November 2014 were excluded in order to assure a minimum follow-up of at least one year. Finally, patients treated within clinical trials with any drug not previously approved were not included in the analysis. The study has been conducted in accordance with the rules of the local Ethics Committee and the Declaration of Helsinki. All patients provided a written consent for use of their clinical data; a separate consent for molecular analyses was obtained. 


\section{Immunohistochemistry and DNA mutation analysis}

Formalin-fixed paraffin-embedded samples were obtained before starting any cancer therapy as a set of ten 5 - $\mu \mathrm{m}$ slides or as uncut tissue blocks. Mutational analysis was performed by Sanger sequencing or by Therascreen EGFR RGQ PCR Kit (Qiagen, Hilden, Germany). Genomic DNA was extracted from tumors lung tissue using the QIAamp DNA FFPE Tissue Kit (Qiagen) according to the manufacturer's protocol. For Sanger sequencing EGFR genes (exons 18, 19, 20 and 21) were amplified using the following primers: for exon 18, forward 5'-TCC AAA TGA GCT GGC AAG TG-3' and reverse 5'-TCC CAA ACA CTC AGT GAA ACA AA-3'; for exon 19, forward 5'-GTG CAT CGC TGG TAA CAT CC-3' and reverse 5'-TGT GGA GAT GAG CAG GGT CT-3'; for exon 20, forward 5'- ATC GCA TTC ATG CGT CTT CA- $3^{\prime}$ and reverse $5^{\prime}$ - ATC CCC ATG GCA AAC TCT TG-3'; for exon 21, forward 5'GCT CAG AGC CTG GCA TGA A-3' and reverse 5'CAT CCT CCC CTG CAT GTG T-3'. PCR conditions were as follows: initial denaturation at $95^{\circ} \mathrm{C}$ for $10 \mathrm{~min}$ followed by 35 cycles at $95^{\circ} \mathrm{C}$ for $40 \mathrm{sec}, 50^{\circ} \mathrm{C}$ for 40 $\mathrm{sec}$ and $72^{\circ} \mathrm{C}$ for $40 \mathrm{sec}$. After visualization onto agarose gel, PCR products were treated with ExoSAP-IT (USB Corp., Cleveland, OH, USA) following the manufacturer's protocol, amplified with BigDye Terminator version 3.1 cycle sequencing kit (Applied Biosystems) using forward and reverse primers and sequenced with an ABI PRISM 3100-Avant Genetic Analyzer (Applied Biosystems). For the therascreen EGFR RGQ PCR Kit (Qiagen) $10 \mathrm{ng}$ of DNA was amplified by real-time PCR in $25 \mu \mathrm{L}$ reactions according to the manufacturer's protocol. Real-time PCR was performed using the Rotor-Gene Q 5plex HRM (QIAGEN). The cycling conditions were as follows: $95^{\circ} \mathrm{C}$ $10 \mathrm{~min}$ and $40 \mathrm{cycles}$ at $95^{\circ} \mathrm{C} 30 \mathrm{~s}, 60^{\circ} \mathrm{C} 60 \mathrm{~s}$. The software program Rotor-Gene Q 2.0.2 was used to process the data. The sample $\mathrm{Ct}$ was compared with the cut-off point for the specific assay (cut-off $\Delta \mathrm{Ct}$ ) according to instructions in the manual.

\section{Statistical analyses}

Primary endpoints were progression free survival (PFS), response rate (RR) and clinical benefit in terms of quality of life (QoL) after first-line therapy with TKIs; overall survival (OS) was considered as secondary endpoint. PFS was calculated from the beginning of first-line therapy until radiologically assessed disease progression or treatment discontinuation for unacceptable toxicity or patient's withdrawal. OS was measured from diagnosis of metastatic disease until death or last followup contact. The outcome was censored if a patient had not progressed or was not dead at the time of last follow-up. Clinical response to treatment was classified as complete response, partial response, stable disease or progressive disease according to the Response Evaluation CriteriaIn Solid Tumors (RECIST) version 1.1.[21]. Kaplan-Meier method and the log-rank test were used to estimate PFS and OS. All reported $p$ values are two-tailed and a level of 0.05 or less was considered statistically significant.

\section{CONFLICTS OF INTEREST}

The authors declare to have no conflict of interest.

\section{Ethical conduct of research}

The study has been conducted in accordance with the rules of the local Ethics Committee and the Declaration of Helsinki. Patient provided a written consent for use of their clinical data.

\section{REFERENCES}

1. Ferlay J, Soerjomataram I, Dikshit R, Eser S, Mathers C, Rebelo M, Parkin DM, Forman D, Bray F. Cancer incidence and mortality worldwide: sources, methods and major patterns in GLOBOCAN 2012. Int J Cancer. 2015; 136(5):E359-86.

2. Howlader N, Noone AM, Krapcho M, Garshell J, Miller D, Altekruse SF, Kosary CL, Yu M, Ruhl J, Tatalovich Z, Mariotto A, Lewis DR, Chen HS, Feuer EJ, Cronin KA (eds). SEER Cancer Statistics Review, 1975-2012, National Cancer Institute. Bethesda, MD, http://seer.cancer. gov/csr/1975_2012/, based on November 2014 SEER data submission, posted to the SEER web site, April 2015.

3. Gridelli C, Shepherd FA. Chemotherapy for elderly patients with non-small cell lung cancer: a review of the evidence. Chest. 2005; 128(2):947-57.

4. Asmis TR, Ding K, Seymour L, Shepherd FA, Leighl NB, Winton TL, Whitehead M, Spaans JN, Graham BC, Goss GD; National Cancer Institute of Canada Clinical Trials Group. Age and comorbidity as independent prognostic factors in the treatment of non small-cell lung cancer: a review of National Cancer Institute of Canada Clinical Trials Group trials. J Clin Oncol. 2008; 26(1):54-9.

5. Paz-Ares L, Soulières D, Melezínek I, Moecks J, Keil L, Mok T, Rosell R, Klughammer B. Clinical outcomes in non-small-cell lung cancer patients with EGFR mutations: pooled analysis. J Cell Mol Med. 2010; 14(1-2):51-69.

6. Lynch TJ, Bell DW, Sordella R, Gurubhagavatula S, Okimoto RA, Brannigan BW, Harris PL, Haserlat SM, Supko JG, Haluska FG, Louis DN, Christiani DC, Settleman J, Haber DA. Activating mutations in the epidermal growth factor receptor underlying responsiveness of non-small-cell 
lung cancer to gefitinib. N Engl J Med 2004; 350: 2129 2139.

7. Pao W, Miller V, Zakowski M, Doherty J, Politi K, Sarkaria I, Singh B, Heelan R, Rusch V, Fulton L, Mardis E, Kupfer D, Wilson R, et al. EGF receptor gene mutations are common in lung cancers from "never smokers" and are associated with sensitivity of tumors to gefitinib and erlotinib. Proc Natl Acad Sci USA 2004; 101: 13306 13311.

8. Inoue A, Kobayashi K, Usui K, Maemondo M, Okinaga S, Mikami I, Ando M, Yamazaki K, Saijo Y, Gemma A, Miyazawa H, Tanaka T, Ikebuchi K, et al. North East Japan Gefitinib Study Group First-line gefitinib for patients with advanced non-small-cell lung cancer harboring epidermal growth factor receptor mutations without indication for chemotherapy. J Clin Oncol. 2009; 27(9):1394-400.

9. Maemondo M, Minegishi Y, Inoue A, Kobayashi K, Harada M, Okinaga S, Morikawa N, Oizumi S, Tanaka T, Isobe H, Kudoh S, Hagiwara K, Nukiwa T, Gemma A. First-line gefitinib in patients aged 75 or older with advanced nonsmall cell lung cancer harboring epidermal growth factor receptor mutations: NEJ 003 study. J Thorac Oncol. 2012; 7(9):1417-22.

10. Peters S, Zimmermann S, Adjei AA. Oral epidermal growth factor receptor tyrosine kinase inhibitors for the treatment of non-small cell lung cancer: comparative pharmacokinetics and drug-drug interactions. Cancer Treat Rev. 2014; 40(8):917-26.

11. Jackman DM, Yeap BY, Sequist LV, Lindeman N, Holmes AJ, Joshi VA, Bell DW, Huberman MS, Halmos B, Rabin MS, Haber DA, Lynch TJ, Meyerson M, et al. Exon 19 deletion mutations of epidermal growth factor receptor are associated with prolonged survival in non-small cell lung cancer patients treated with gefitinib or erlotinib. Clin Cancer Res. 2006; 12:3908-3914.

12. Morita S, Okamoto I, Kobayashi K, Yamazaki K, Asahina H, Inoue A, Hagiwara K, Sunaga N, Yanagitani N, Hida T, Yoshida K, Hirashima T, Yasumoto K, et al. Combined survival analysis of prospective clinical trials of gefitinib for non-small cell lung cancer with EGFRmutations. Clin Cancer Res. 2009; 15(13):4493-8.

13. Riely GJ, Pao W, Pham D, Li AR, Rizvi N, Venkatraman ES, Zakowski MF, Kris MG, Ladanyi M, Miller VA. Clinical course of patients with non-small cell lung cancer and epidermal growth factor receptor exon 19 and exon 21 mutations treated with gefitinib or erlotinib. Clin Cancer Res.2006; 12:839-844.

14. Wheatley-Price P, Ding K, Seymour L, Clark GM, Shepherd FA. Erlotinib for advanced non-small-cell lung cancer in the elderly: an analysis of the National Cancer Institute of Canada Clinical Trials Group Study BR.21. J Clin Oncol. 2008; 26(14):2350-7..

15. Yoshioka H, Komuta K, Imamura F, Kudoh S, Seki A, Fukuoka M. Efficacy and safety of erlotinib in elderly patients in the phase IV POLARSTAR surveillance study of Japanese patients with non-small-cell lung cancer. Lung Cancer. 2014; 86(2):201-6.

16. Sotaniemi EA, Arranto AJ, Pelkonen O, Pasanen M. Age and cytochrome P450-linked drug metabolism in humans: an analysis of 226 subjects with equal histopathologic conditions. Clin Pharmacol Ther. 1997; 61(3):331-9.

17. Cotreau MM, von Moltke LL, Greenblatt DJ. The influence of age and sex on the clearance of cytochrome P450 3A substrates. Clin Pharmacokinet. 2005;44(1):33-60.

18. Tiseo M, Andreoli R, Gelsomino F, Mozzoni P, Azzoni C. Correlation between erlotinib pharmacokinetics, cutaneous toxicity and clinical outcomes in patients with advanced non-small cell lung cancer (NSCLC). Lung cancer. 2014; 83(2):265-71.

19. Wind S, Schmid M, Erhardt J, Goeldner RG Pharmacokinetics of afatinib, a selective irreversible ErbB family blocker, in patients with advanced solid tumours. Clin pharmacokinet. 2013; 52(12):1101-9.

20. Ranson M, Hammond LA, Ferry D, Kris M, Tullo A, Murray PI, Miller V, Averbuch S, Ochs J, Morris C, Feyereislova A, Swaisland H, Rowinsky EK. ZD1839, a selective oral epidermal growth factor receptor-tyrosine kinase inhibitor, is well tolerated and active in patients with solid, malignant tumors: results of a phase I trial. J Clin Oncol. 2002; 20(9):2240-50.

21. Eisenhauer EA, Therasse P, Bogaerts J, Schwartz LH, Sargent D, Ford R, Dancey J, Arbuck S, Gwyther S, Mooney M, Rubinstein L, Shankar L, Dodd L, et al. New response evaluation criteria in solid tumours: revised RECIST guideline (version 1.1). Eur J Cancer. 2009;45(2):228-47. 